\title{
Arduino based Animal Intrusion Prevention System
}

\author{
Padmanabhan Subbulakshmi \\ PD-Eng-Platform(Department), StubHub, San Francisco, CA-94105, \\ subpadmanabhan@stubhub.com
}

\begin{abstract}
Man-wild elephant conflict has been on the rise in the forest border areas with herds of wild elephants straying into human habitation and destroying life and property. In this paper we propose a method to prevent wild elephants from straying into human habitation. If an elephant comes very close to the forest boundary then its presence is detected by an IR sensor which triggers an alarm to scare it away back into the forest. If the elephant still doesn't go back and comes closer to the forest boundary, then another IR sensor will detect its presence and the relay is activated for the current to pass through the forest wire fence,preventing the elephant from moving out of the forest area. This paper further addresses the issue of movement of elephants to safer zones in the event of floods in the surrounding area. To address this issue both the IR sensors are disabled. A disabled switch is used, which in turn causes both the IR sensors to be disabled.
\end{abstract}

Key words:Arduino, Intrusion Prevention System, L293D

Corresponding Author:PadmanabhanSubbulakshmi

\section{INTRODUCTION}

In an article in 'Times of India' about 22 elephants were electrocuted at private plantations in 2010-2015 period in tamilnadu.. The reason was that there was no proper mechanism to drive the elephants back into forest and the owners used domestic supply (230V) supply to their electric fences to protect their plantations. Permissible electricity supply to an electric fence around a farm is around 12 volts of pulsating power. The need for a proper animal intrusion system is to be designed so that no harm is encountered for both the human property or to the animal itself. . In this project we have developed two line of defense system. This defense system can beimplemented in different plantations close to the forest area. The first line of defense contains a sensor that actuates when the animal enters in to a particular range of area of theinfra-red sensor. When the infra-red sensor senses the animal it triggers an alarm which creates a sound that will irritate the animal and force it to go back to the place where it has come from. Due to unforeseen situations if the animal proceeds further then it will enter in to the second line of defense in which there will be another IR sensor which triggers the relay. Therelay operates with a 12 volt. After this relay gets $\mathrm{ON}$ it will turn on the power circuit and the live wire get activated. This activation will take place for $5 \mathrm{sec}$ which will give the animal an electric shock ( $12 \mathrm{~V}$ pulsed), so that the animal goes back to the place where it has come from. In this process there is no harm to both mankind and wild life as the shock lasts for 5 second and hence preventscasualties due to electrocution and the life of the animal is saved.

\section{METHODOLOGY}

A prototype is designed and developed using Arduino.Two infra-red sensors are used to detect the animal entering into the line of defenses. When the animal's presence is sensed by the first sensor, buzzer is activated by the processor and scare the animal away .Even after 
this precautionary measure if the animal further moves forward, the second sensor detects its presence and the relay is activated by the processor and causes the power to be ON. The relay used is energized by a voltage of 12 volts, which is generated by L293D the circuit receives a voltage of 12 volt through an external power source which is a battery in this prototype used. If the disable switch is high then all the sensors are disabled. This can be used in case of some forest fire etc. when we want the animal to get to a safer place.

The block diagram of the entire process is presented in Figure. 1

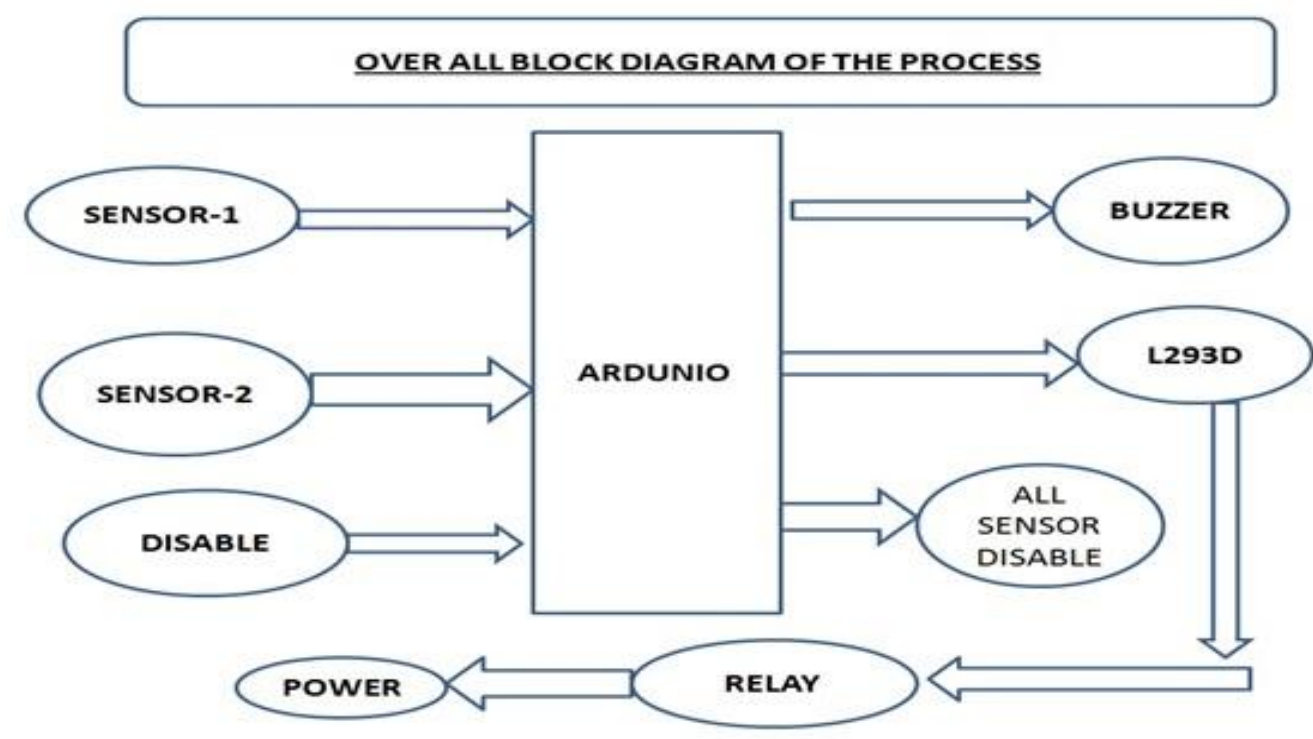

The flowchart of the algorithm implementation is presented in Fig.2

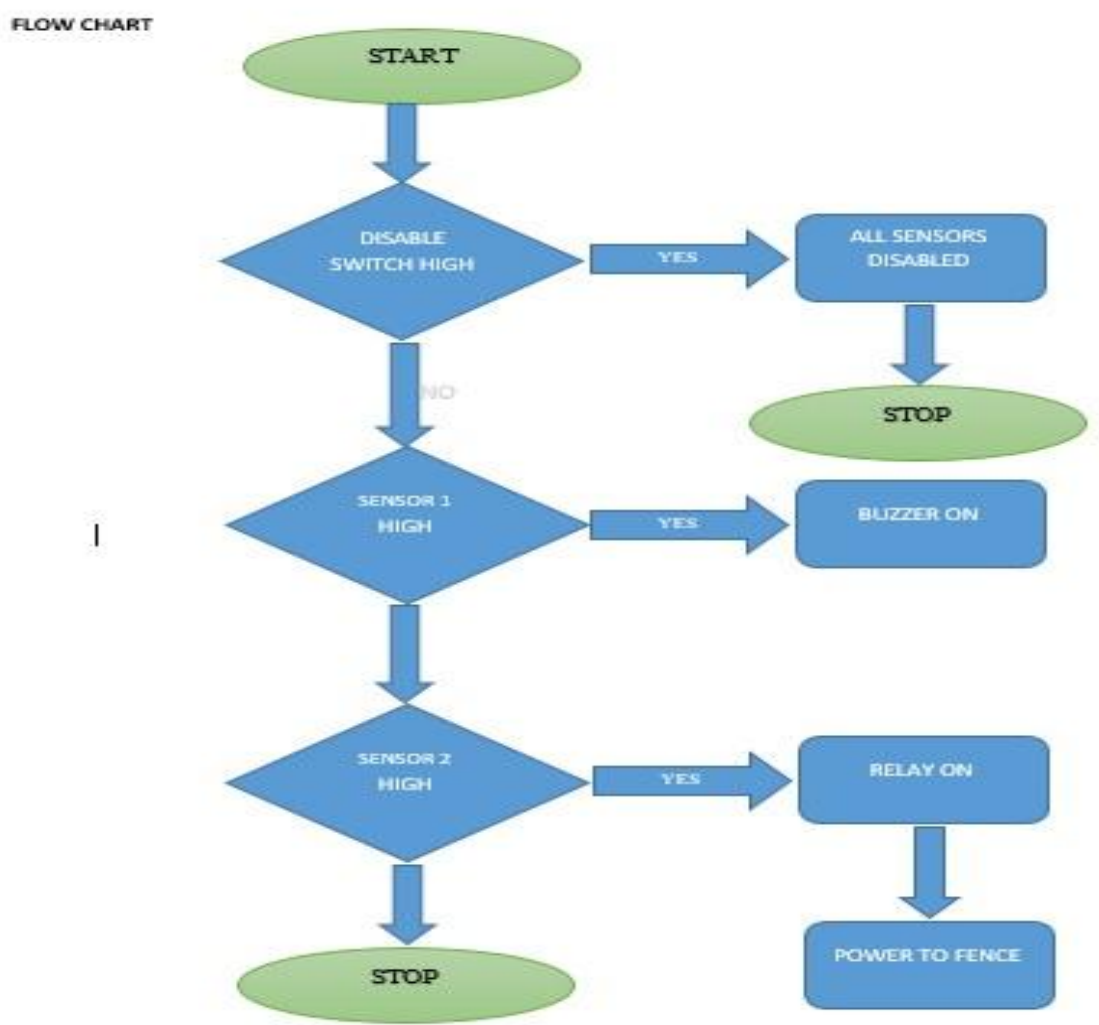

FIG.2 flow chart of the algorthm 


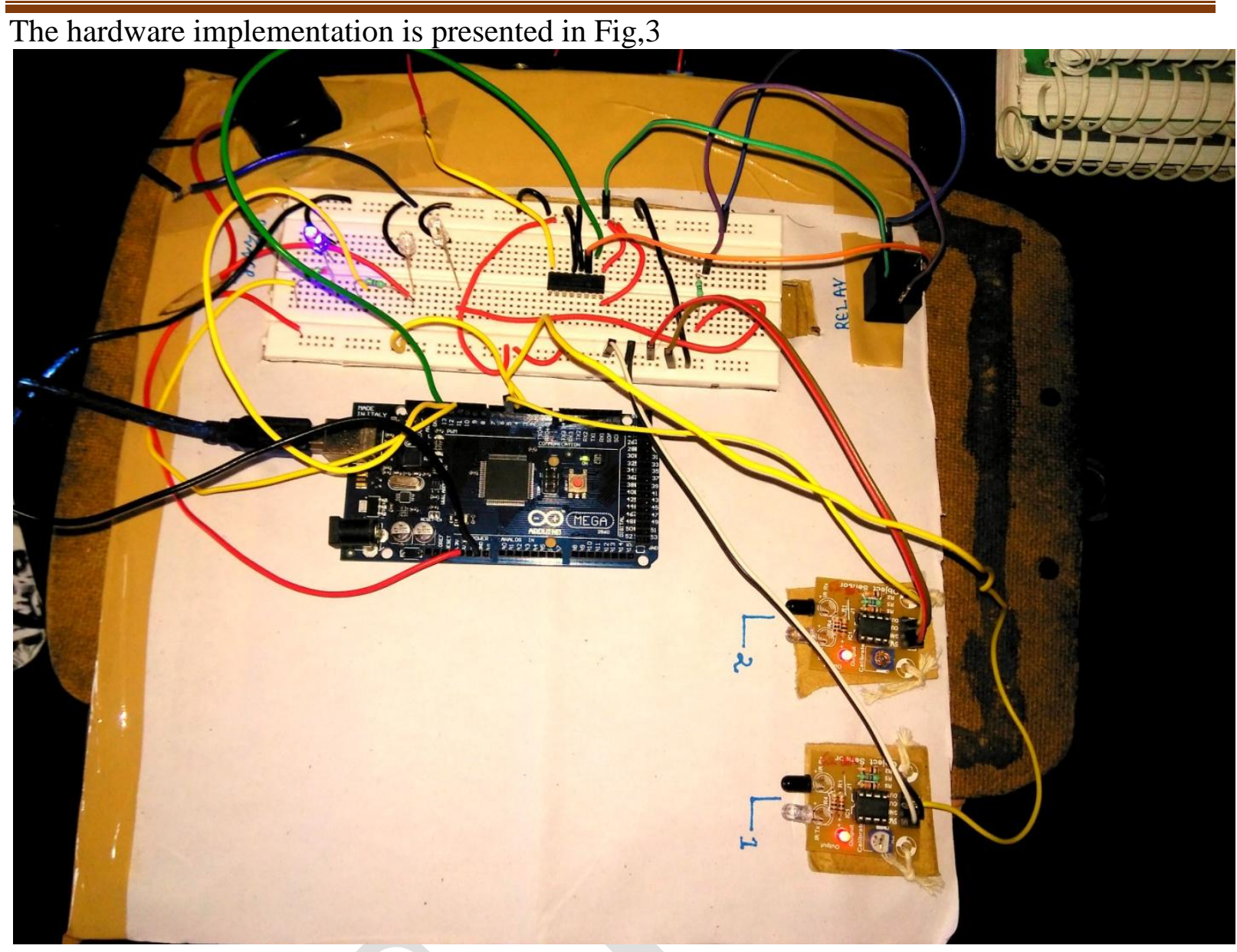

\section{CONCLUSION}

The model was tested in a laboratory scale and was found to be working properly as per the requirement. From the above method it can be concluded that if such systems are implemented there will be minimal or no loss of human and wild life. The work does not involve heavy cost as the components are easily available. We are not using the 230 volt line to electrocute the animals so it is not violating any wild life protection rule. If this project can be implemented in real life scenarioit will be more beneficial to both human and wild life.

\section{REFERENCES}

[1] https://www.arduino.cc/

[2] https://www.arduino.cc/en/Guide/Introduction

[3] https://en.wikipedia.org/wiki/Motor_driver_L293d

[4] http://www.futurlec.com/Relays/JQC-3FF-12.shtml

[5] S. J. Sugumar1 and R. Jayaparvathy, An Improved Real Time Image Detection System for Elephant Intrusion along the Forest Border Areas, The Scientific World Journal Volume 2014 (2014), Article ID 393958

[6] C. Arivazhagan and B. Ramakrishnan, "Conservation perspective of Asian Elephants (Elephasmaximus) in Tamil Nadu, Southern India," International Journal of Biotechnology, vol. 1, pp. 15-22, 2010. 